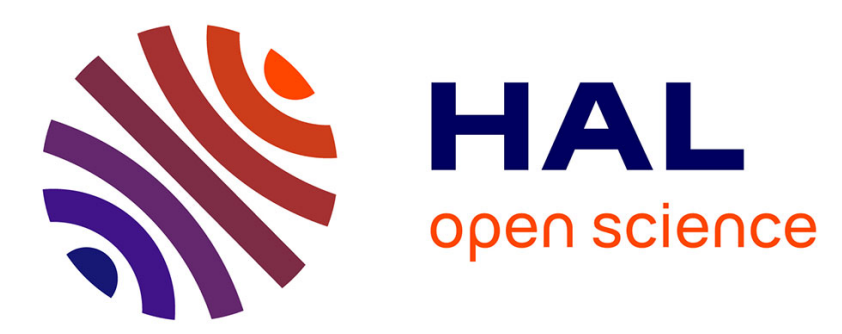

\title{
Assessment of a microwave-assisted recycling process for the recovery of high-quality aggregates from concrete waste
}

Kathy Bru, Solène Touzé, Florent Bourgeois, Nicholas Lippiatt, Yannick

Ménard

\section{To cite this version:}

Kathy Bru, Solène Touzé, Florent Bourgeois, Nicholas Lippiatt, Yannick Ménard. Assessment of a microwave-assisted recycling process for the recovery of high-quality aggregates from concrete waste. International Journal of Mineral Processing, 2014, vol. 126, pp. 90-98. 10.1016/j.minpro.2013.11.009 . hal-00920886

\section{HAL Id: hal-00920886 https://hal.science/hal-00920886}

Submitted on 19 Dec 2013

HAL is a multi-disciplinary open access archive for the deposit and dissemination of scientific research documents, whether they are published or not. The documents may come from teaching and research institutions in France or abroad, or from public or private research centers.
L'archive ouverte pluridisciplinaire HAL, est destinée au dépôt et à la diffusion de documents scientifiques de niveau recherche, publiés ou non, émanant des établissements d'enseignement et de recherche français ou étrangers, des laboratoires publics ou privés. 


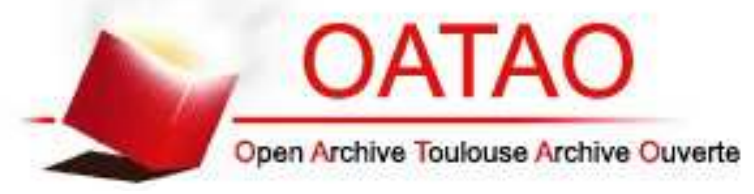

\section{Open Archive TOULOUSE Archive Ouverte (OATAO)}

OATAO is an open access repository that collects the work of Toulouse researchers and makes it freely available over the web where possible.

This is an author-deposited version published in : http://oatao.univ-toulouse.fr/ Eprints ID : 10579

To link to this article : DOI:10.1016/j.minpro.2013.11.009

URL : http://dx.doi.org/10.1016/j.minpro.2013.11.009

To cite this version : Bru, Kathy and Touzé, Solène and Bourgeois, Florent and Lippiatt, Nicholas and Ménard, Yannick. Assessment of amicrowaveassisted recycling process for the recovery of high-quality aggregates from concrete waste. (2014) International Journal of Mineral Processing, vol. 126 . pp. 90-98.

ISSN 0301-7516

Any correspondance concerning this service should be sent to the repository administrator: staff-oatao@ listes-diff.inp-toulouse.fr 


\title{
Assessment of a microwave-assisted recycling process for the recovery of high-quality aggregates from concrete waste
}

\author{
Kathy Bru ${ }^{a, *}$, Solène Touzé ${ }^{a}$, Florent Bourgeois ${ }^{b}$, Nicholas Lippiatt ${ }^{b}$, Yannick Ménard ${ }^{a}$ \\ a BRGM, Water, Environment and Ecotechnologies Division - Waste and Raw Materials \& Recycling Unit, 3 Avenue Claude Guillemin, BP 36009 , Orléans 45060 Cedex 2, France \\ b Laboratoire de Génie Chimique, UMR CNRS 5503, Université de Toulouse, 4 Allée Emile Monso, BP 44362, Toulouse 31432 Cedex 4, France
}

Article history:

Received 9 July 2013

Received in revised form 7 November 2013

Accepted 17 November 2013

Available online 1 December 2013

Keywords:

Concrete

Recycling

Microwaves

Liberation

Selective fragmentation

\begin{abstract}
This study presents an innovative method for concrete waste up-cycling based on concrete weakening through microwave heating before impact crushing. Two series of tests were conducted in order to assess the influence of the aggregate properties (size distribution, mineralogical nature) and the influence of the operating conditions of the microwave heating pretreatment on concrete fragmentation; and thus to evaluate the feasibility and the robustness of this process. Experiments were carried out on lab-made, cylindrical concrete specimens and on no-slump concrete waste with a multimode cavity microwave equipment $(2.45 \mathrm{GHz}, 6 \mathrm{~kW})$ and an impact crusher. Results showed that microwave heating always induced an embrittlement of concrete samples which resulted in lower fracture energy, higher fragmentation of samples and higher liberation of aggregates (i.e. free of cement paste). A microwave-assisted comminution process is therefore an effective recycling technique for the recovery of high-quality aggregates from concrete waste.
\end{abstract}

\section{Introduction}

Concrete is the world's most widely used construction material but its production has negative impacts on the environment and on our future capacity to meet an ever-increasing demand. The global construction industry uses approximately 1.5 billion tonnes of cement and 9 billion tonnes of sand, gravel, and crushed rock every year and the demand for concrete is expected to grow to approximately 16 billion tonnes a year by 2050 (Mehta and Monteiro, 2005). However, mining large quantities of raw materials often results in extensive deforestation or denudation and top-soil loss (Mehta, 2001). A growing demand for aggregates, especially in large metropolitan areas, leads to increased transportation distances, costs and by extension environmental impacts. This leads to a rising demand for alternative aggregate resources such as recycled aggregates from Construction and Demolition Waste (CDW).

The traditional recycling circuit for CDW includes crushing steps that do not permit recovery of liberated, i.e. cement free, aggregates. Indeed, these techniques apply high compressive stresses that are rather inefficient for the intended objective. Because of the high compressive strength of concrete, they yield extensive comminution not only of the concrete matrix but also of the aggregates themselves. Moreover, the amount of liberated aggregates is very low. As a result, recycled concrete aggregates contain various amounts of adhered cement mortar which

\footnotetext{
* Corresponding author at: BRGM, Water, Environment and Ecotechnologies Division - Waste and Raw Materials \& Recycling Unit, 3 Avenue Claude Guillemin, BP 36009, 45060 Orléans Cedex, France. Tel.: + 332386447 61; fax: + 33238643680.

E-mail address: k.bru@brgm.fr (K. Bru).
}

negatively affect the workability and mechanical properties of concrete (Kim et al., 2012; Ulsen et al., 2013). Therefore, recycled concrete aggregates are not beneficiated as aggregates for new concrete manufacturing but they are mainly downcycled as road pavement materials. A breakthrough method for liberating aggregates from concrete waste is then required to produce high quality recycled aggregates.

Different mineral dressing operations have been proposed to remove the cement paste from coarse recycled aggregates. Among these techniques, microwave heating technology has recently been recognized as one possible solution for producing clean aggregates from concrete waste (Tsujino et al., 2008; Akbarnezhad et al., 2011; Lippiatt and Bourgeois, 2012; Menard et al., 2013). This technology uses microwave electromagnetic energy to induce concrete embrittlement. Its principle is based on the selective effects of internal heating on different mineral phases when submitted to microwaves which create stresses due to differential thermal expansion. Moreover, microwave heating can also generate significant pore pressures due to the rapid formation of steam from water within the material. These internal mechanical stresses produce fractures, especially at the interfacial transition zone (ITZ) which is located between aggregates and the cement paste, leading therefore to a weakening of the material (Lippiatt and Bourgeois, 2012). Regarding liberation of aggregates, i.e. production of aggregates without adhering cement paste, Akbarnezhad et al. (2011) reported that microwave heating alone allowed partial liberation of aggregates from laboratory cast concrete samples. When a mechanical rubbing stage was used after microwave heating, then aggregates of higher quality were obtained since rubbing improved the removal of adhering weakened cement paste and the breakage of the mortar lumps 
Table 1

Composition and properties of the concrete specimens.

\begin{tabular}{|c|c|c|c|c|c|}
\hline \multirow[b]{2}{*}{ Mineralogical nature of aggregates } & & SC_fine & SC_medium & SC_coarse & S_medium \\
\hline & & \multicolumn{3}{|c|}{ Alluvial silico-calcareous aggregates } & Crushed siliceous aggregates \\
\hline \multirow[t]{5}{*}{ Particle size distribution (in wt.\%) } & $8-20 \mathrm{~mm}$ & & 5.5 & 3 & 1.9 \\
\hline & $6.3-8 \mathrm{~mm}$ & & 22.5 & 64 & 19.4 \\
\hline & $4-6.3 \mathrm{~mm}$ & & 35.5 & 33 & 38.5 \\
\hline & $2-4 \mathrm{~mm}$ & 83 & 30 & & 32 \\
\hline & $<2 \mathrm{~mm}$ & 17 & 6.5 & & 8.3 \\
\hline Compressive strength (MPa) & & 30.3 & 19.8 & 13.7 & 22.7 \\
\hline
\end{tabular}

(Akbarnezhad et al., 2011). These findings were similar to the results obtained by Lippiatt and Bourgeois (2012) who observed improved liberation of both aggregates and cement phases after impact fragmentation of microwave heated lab made concrete samples. These results confirm the potential of microwave heating for selective liberation of concrete's raw constituents i.e. cement paste and aggregates, hence their possible reuse as raw constituents for clinker manufacturing and concrete production respectively. Another technology based on microwave heating was investigated by Tsujino et al. (2008). This technology involved aggregate surface modification by applying a coating of a strongly dielectric binder to the surface of coarse aggregates before being used to make concrete, with a twofold objective: increasing concrete strength and improving aggregate liberation when processed with microwave heating. Recycled coarse aggregates were of high quality (Tsujino et al., 2008; Noguchi et al., 2011). Although it was demonstrated that this technique has potential for improving concrete waste recycling, its requirement of specially designed material (i.e. concrete with modified surface aggregates) makes it unusable on existing concrete waste.

This work aimed to assess the feasibility of combining microwave heating pretreatment and impact crushing for achieving selective fragmentation and liberation of concrete's natural aggregates. It investigated the effect of aggregate properties (size distribution, mineralogy) and process properties (power and exposure time) on process performance. Its sensitivity to each of these variables was also studied.

\section{Materials and methods}

\subsection{Concrete samples}

Two types of concrete samples were used in this study: lab-made concrete specimens and no-slump concrete waste samples.

Lab-made concrete specimens were cast as cylinders $40 \mathrm{~mm}$ in diameter and $80 \mathrm{~mm}$ in height for this investigation. They were manufactured using CEM $152.5 \mathrm{~N}$ Portland cement, cement to concrete ratio of $400 \mathrm{~kg} / \mathrm{m}^{3}$ (wet basis) and a water-to-cement ratio of 0.6 (mass basis). Aggregates used were either silico-calcareous (SC) or siliceous (S). Three aggregate sizes were used (fine, medium and coarse) but the volume fraction of aggregates was kept constant at $0.63 \mathrm{~m}^{3} / \mathrm{m}^{3}$ of concrete on a wet basis. The composition and properties of these specimens are given in Table 1. As shown in Table 1, these formulations led to normal strength concretes.

Table 2

Composition and properties of the no-slump concrete waste

\begin{tabular}{clc} 
Mineralogical nature of aggregates & & $\begin{array}{c}\text { Alluvial siliceous and } \\
\text { calcareous aggregates }\end{array}$ \\
\hline Average particle size distribution & $8-20 \mathrm{~mm}$ & 53.8 \\
of the aggregates (in wt.\%) & $6.3-8 \mathrm{~mm}$ & 7.5 \\
& $2-6.3 \mathrm{~mm}$ & 3.9 \\
& $<2 \mathrm{~mm}$ & 34.8 \\
Compressive strength $\left(\mathrm{N} / \mathrm{mm}^{2}\right)$ & & 39.2 \\
\hline
\end{tabular}

No-slump concrete waste samples, commonly known as dry cast concrete, correspond to the waste of concrete delivered by dump trucks i.e. the excess concrete which was not used at a construction site. It was collected from a French company specializing in earthwork and public works. This concrete was made with $80.3 \%$ of alluvial siliceous and calcareous aggregates, of which $61.3 \%$ was coarse aggregates $(6.3-20 \mathrm{~mm})$ and $38.7 \%$ was sand $(0-4 \mathrm{~mm}), 17.0 \%$ of CEM $152.5 \mathrm{~N}$ Portland cement and $2.7 \%$ of water. The water-to-cement ratio was 0.16 . The composition and properties of this concrete waste are given in Table 2. After collection, this concrete was cast into a slab and left to cure for $\mathbf{5}$ months. Once cured the concrete was crushed in a jaw crusher with a closedside setting of $80 \mathrm{~mm}$.

\subsection{Experimental set-up}

Microwave heating was carried out in a $2.45 \mathrm{GHz}$ laboratory microwave oven manufactured by Sairem. This equipment generates up to $6 \mathrm{~kW}$ of microwave power in a multimode cavity. Concrete was then comminuted using a laboratory Hazemag impact crusher with rotation speed of $290 \mathrm{rpm}$.

The performance of the microwave heating process, as defined by the selectivity of the fragmentation process, was evaluated through batch tests performed on $400-450 \mathrm{~g}$ concrete samples with size between 50 and $80 \mathrm{~mm}$.

- The first series of experiments was carried out with the lab-made concrete specimens in order to investigate the influence of aggregate properties.

- The second series of experiments was performed using the noslump concrete waste samples in order to study the effect of operating variables, namely power ( $\mathrm{kW}$ ) and exposure time (min) and thus energy absorbed by the sample $(\mathrm{kWh} / \mathrm{t})$. The latter was

Table 3

Operating conditions of the microwave heating stage before impact crushing.

\begin{tabular}{|c|c|c|c|c|c|}
\hline & & \multicolumn{2}{|c|}{$\begin{array}{l}\text { Operating conditions of } \\
\text { the microwave } \\
\text { heating stage }\end{array}$} & \multirow[t]{2}{*}{$\begin{array}{l}\text { Energy absorbed } \\
\text { by the sample } \\
(\mathrm{kWh} / \mathrm{t})\end{array}$} & \multirow[t]{2}{*}{$\begin{array}{l}\text { Replicates } \\
\text { number }\end{array}$} \\
\hline & & $\begin{array}{l}\text { Power } \\
\text { (kW) }\end{array}$ & $\begin{array}{l}\text { Exposure time } \\
\text { (min) }\end{array}$ & & \\
\hline \multirow[t]{8}{*}{ Series $n^{\circ} 1$} & SC_fine & - & - & - & $\geq 2$ \\
\hline & & 4.5 & 0.5 & 37.7 & \\
\hline & SC_medium & - & - & - & \\
\hline & & 4.5 & 0.5 & 36.5 & \\
\hline & SC_coarse & - & - & - & \\
\hline & & 4.5 & 0.5 & 37.6 & \\
\hline & S_medium & - & - & - & \\
\hline & & 4.5 & 0.5 & 36.5 & \\
\hline \multirow[t]{5}{*}{ Series $n^{\circ} 2$} & No-slump & - & - & - & $\geq 3$ \\
\hline & concrete waste & 1 & 0.5 & 7.1 & \\
\hline & & 4.5 & 0.5 & 32.4 & \\
\hline & & 1 & 5 & 77.2 & \\
\hline & & 4.5 & 5 & 348.6 & \\
\hline
\end{tabular}




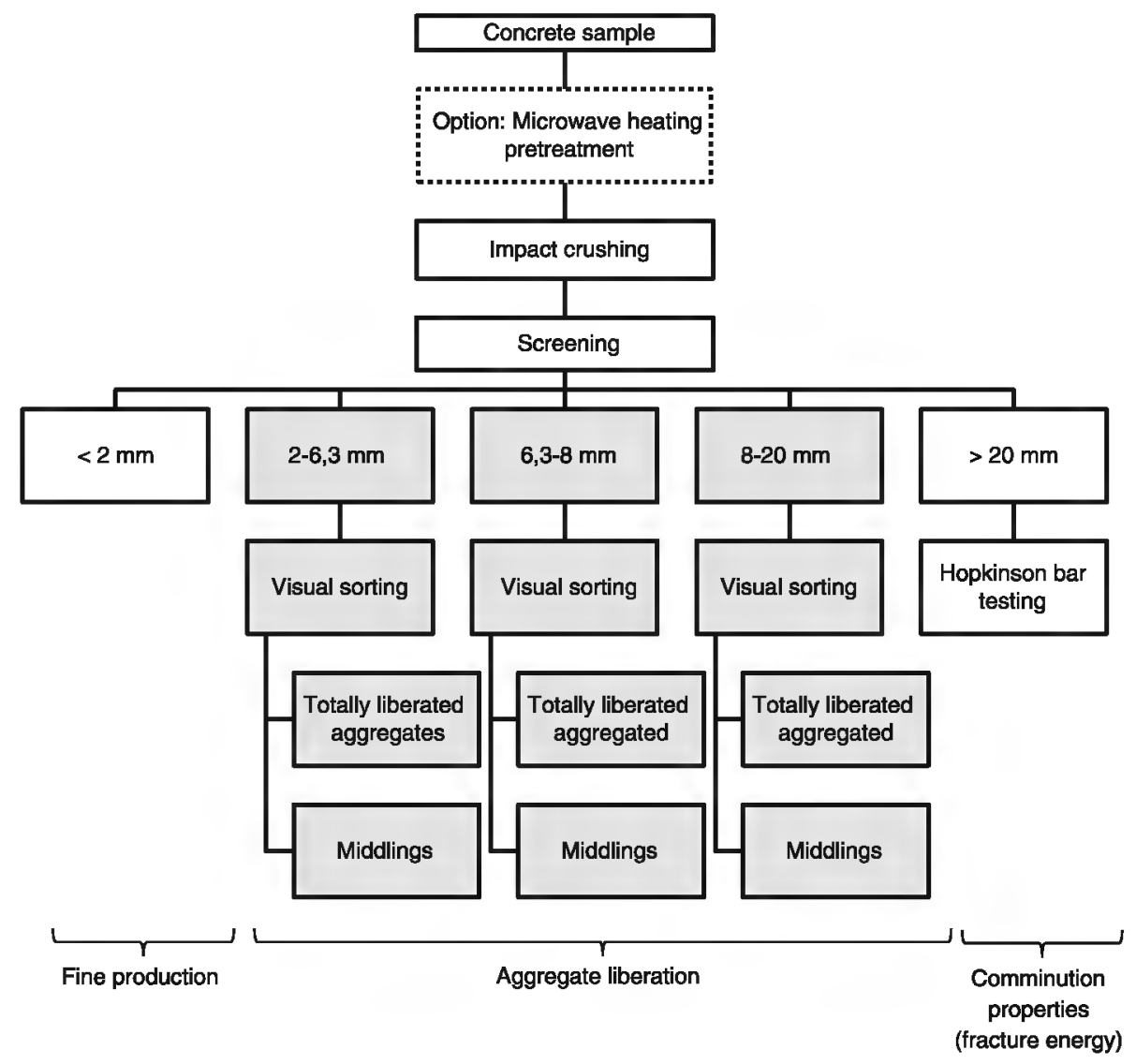

Fig. 1. Experimental testing and product analysis protocols.

experimentally evaluated to about $40 \%$ of the incident microwave energy calculated as the product of power and exposure time.

Due to the heterogeneity of concrete waste, the significance of the results of the tests performed in the second series was analyzed by statistical means. Operating conditions of these tests are reported in Table 3. In both cases, replicates were performed so as to ensure reproducibility of the tests.

\subsection{Characterization methods}

In each experiment, the particle size distribution of the fragments after crushing was measured. Five sieves were used: $2 \mathrm{~mm}, 6.3 \mathrm{~mm}, 8 \mathrm{~mm}$,

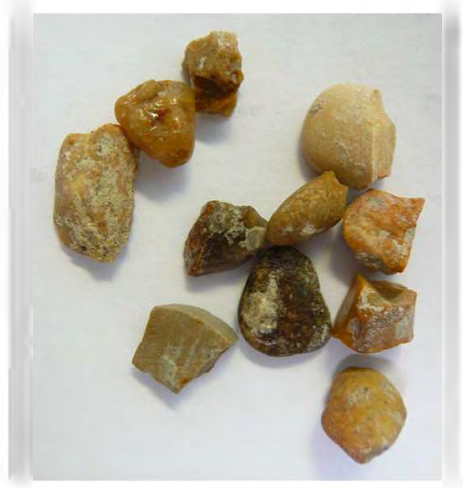

Totally liberated aggregates.

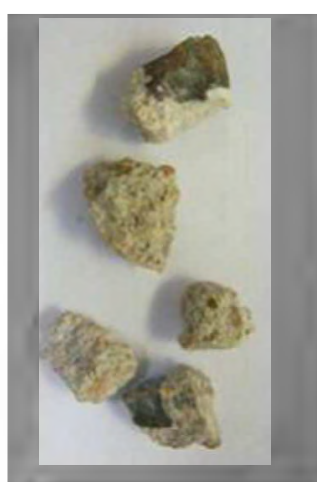

Unliberated aggregates, exhibiting various degrees of adhering cement paste.
Fig. 2. Pictures of the aggregate liberation.
$20 \mathrm{~mm}$ and $31.5 \mathrm{~mm}$. As shown in Fig. 1, the performance of the process, i.e. the sequence of microwave heating followed by impact crushing, was assessed through the embrittlement of the specimens, the liberation of aggregates and the production of fines.

i. The mechanical strength of individual concrete particles, untreated or treated with microwaves, was evaluated using a short vertical Hopkinson bar, an apparatus which is dedicated to a single-particle impact breakage testing (Bourgeois and Banini, 2002). The test gives

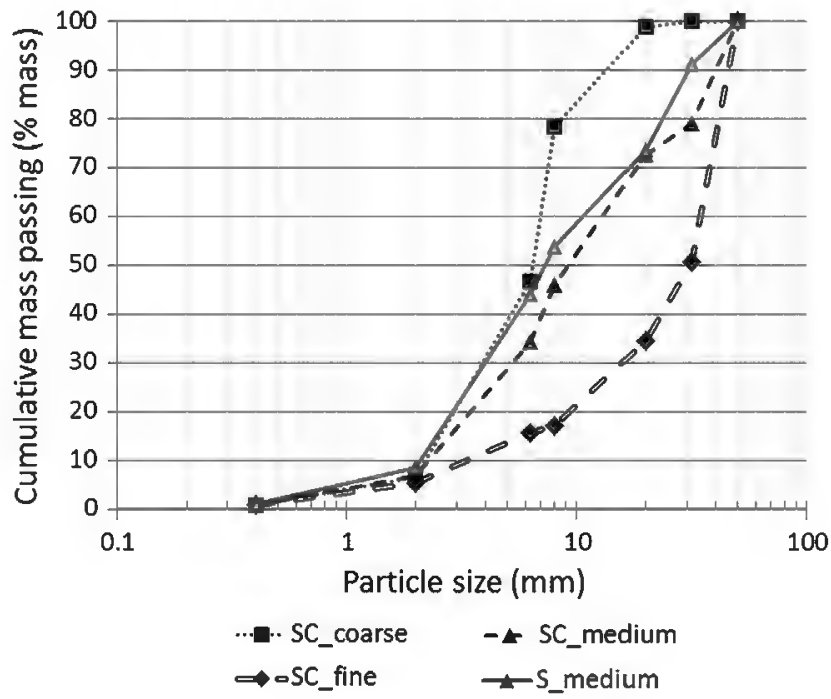

Fig. 3. Size distribution of fragments after impact crushing of 4 types of concrete specimens (see Table 1) 
Table 4

Fracture energy of concrete samples SC_coarse, SC_medium, SC_fine and S_medium before impact crushing.

\begin{tabular}{lll}
\hline & $\begin{array}{l}\text { Fracture energy } \\
(\mathrm{Wh} / \mathrm{t})\end{array}$ & \\
\cline { 2 - 3 } & Mean & $\begin{array}{l}\text { Standard deviation } \\
\text { of the mean }\end{array}$ \\
\hline SC_coarse & 5.5 & 0.1 \\
SC_medium & 10.4 & 0.3 \\
SC_fine & 12.2 & 2.5 \\
S_medium & 9.7 & 0.1 \\
\hline
\end{tabular}

Table 5

Liberation degree of aggregates in fragment size of 2-20 mm after impact crushing of concrete specimens SC_fine, SC_medium, SC_coarse and S_medium.

\begin{tabular}{|c|c|c|c|c|}
\hline & \multicolumn{2}{|c|}{$\begin{array}{l}\text { Fragment size of } 2-20 \mathrm{~mm} \\
\text { (wt.\%) }\end{array}$} & \multicolumn{2}{|c|}{$\begin{array}{l}\text { Liberation degree of aggregates } \\
\text { in fragment size of } 2-20 \mathrm{~mm} \\
\text { (wt.\%) }\end{array}$} \\
\hline & Mean & $\begin{array}{l}\text { Standard deviation } \\
\text { of the mean }\end{array}$ & Mean & $\begin{array}{l}\text { Standard deviation } \\
\text { of the mean }\end{array}$ \\
\hline SC_coarse & 92.1 & 0.8 & 71.6 & 1.3 \\
\hline SC_medium & 65.8 & 2.5 & 45.3 & 3.5 \\
\hline SC_fine & 29.0 & 0.2 & 19.1 & 1.8 \\
\hline S_medium & 65.1 & 1.3 & 65.7 & 2.2 \\
\hline
\end{tabular}

(a)

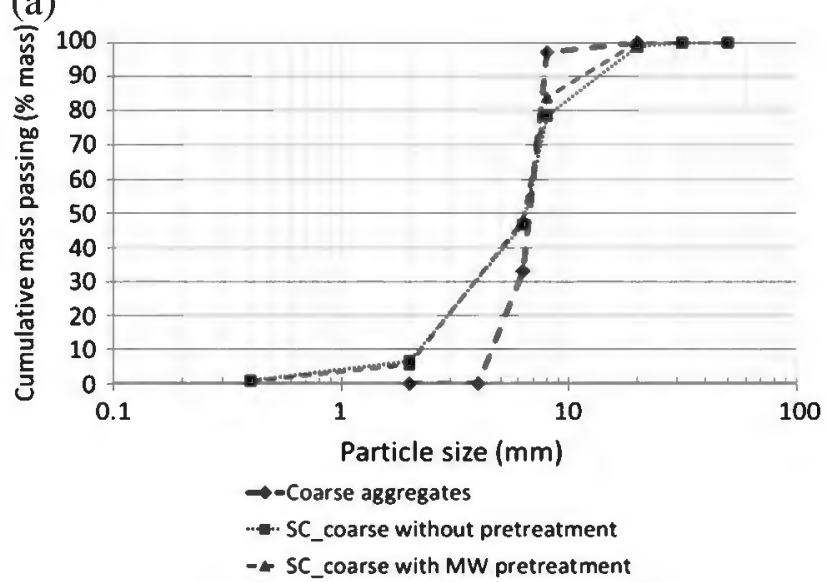

(c)

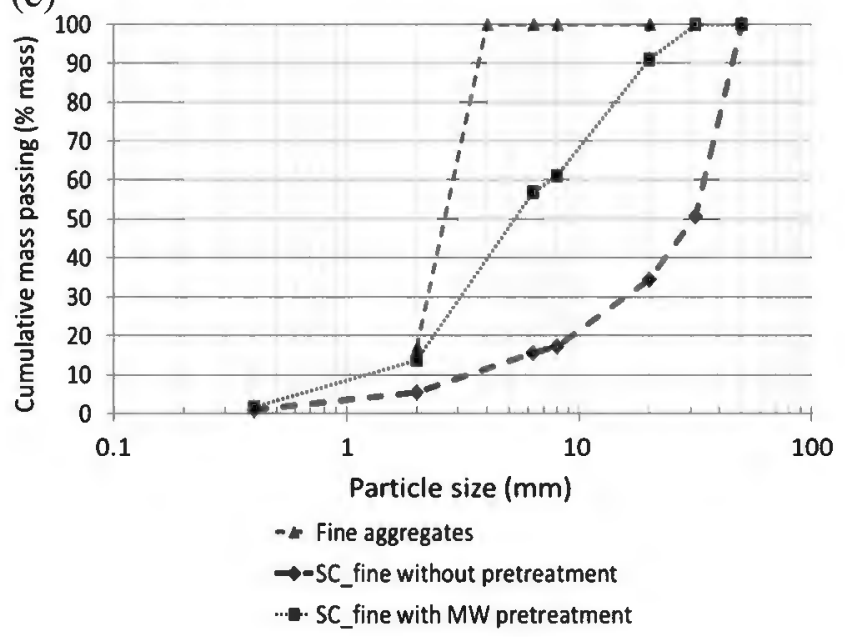

indications of a particle's degree of embrittlement through measurement of properties such as mass specific fracture energy and particle strength. In this study, the mechanical strength was only performed on samples with size larger than $20 \mathrm{~mm}$ due to the aggregate maximum size $(20 \mathrm{~mm})$. Mass specific fracture energy was used to compare the relative level of embrittlement of concrete specimens.

ii. Liberation degree is defined as the ratio between the mass content of liberated aggregates and the mass content of all aggregates included in a given fragment size fraction. As defined by Tomas et al. (1999), totally liberated aggregates means that no hardened cement paste is adhered and no liberation means that the aggregates are still bonded in the hardened cement paste bulk matrix (Fig. 2), In this study, liberation degree was measured by visual sorting. Due to the difficulty of sorting the finer particle size fractions, the liberation degree of aggregates was only measured on $2-20 \mathrm{~mm}$ particles. The effectiveness of this method for liberation quantification was evaluated through measurements of liberated aggregates and middling's water absorption according to the French standard (NF EN, 1097-6, 2001). Results showed that water absorption was about $2.5 \%$ ior liberated aggregates and 9.7\% for middling. According to the French standard (NF P18-545, 2001) the limit value of water absorption for natural aggregates in categories A, B and C are fixed at 2.5\%, 5\% and $6 \%$ respectively. This indicates that the aggregates classed as "liberated" in this experiment are of a high quality.

iii. Production of fine fractions refers to the amount of particles with size lower than $2 \mathrm{~mm}$

(b)

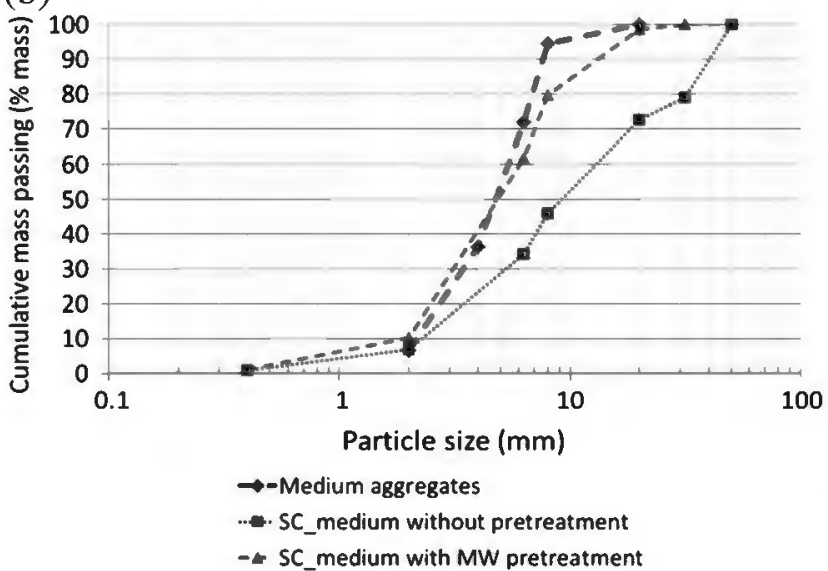

(d)

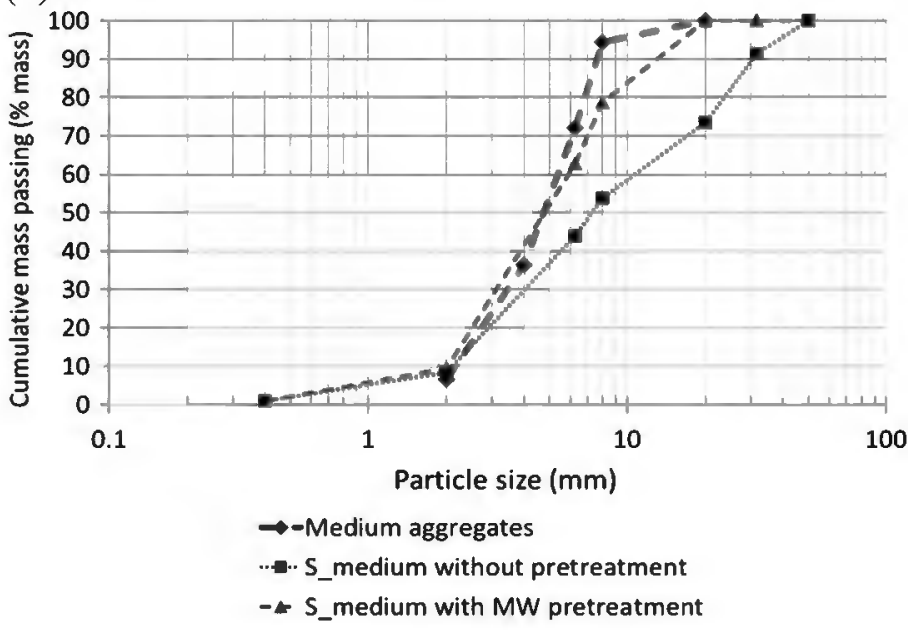

Fig.4. Fragment size distribution after impact crushing with and without microwave (MW) pretreatment of concrete specimens SC_coarse (a), SC_medium (b), SC_fine (c) and S_medium (d). 
Table 6

Fragment size distribution after impact crushing of concrete specimens SC_coarse, SC_medium, SC_fine, S_coarse and S_medium with and without a microwave (MW) pretreatment at $4.5 \mathrm{~kW}-30 \mathrm{~s}$.

\begin{tabular}{|c|c|c|c|c|c|c|c|}
\hline & & \multicolumn{2}{|c|}{$\begin{array}{l}<2 \mathrm{~mm} \\
(\mathrm{wt}, \%)\end{array}$} & \multicolumn{2}{|c|}{$\begin{array}{l}2-20 \mathrm{~mm} \\
\text { (wt.\%) }\end{array}$} & \multicolumn{2}{|c|}{$\begin{array}{l}>20 \mathrm{~mm} \\
(w t . \%)\end{array}$} \\
\hline & & Mean & $\begin{array}{l}\text { Standard deviation } \\
\text { of the mean }\end{array}$ & Mean & $\begin{array}{l}\text { Standard deviation } \\
\text { of the mean }\end{array}$ & Mean & $\begin{array}{l}\text { Standard deviation } \\
\text { of the mean }\end{array}$ \\
\hline \multirow[t]{2}{*}{ SC_coarse } & Impact crushing & 6.7 & 0.4 & 92.1 & 0.8 & 1.2 & 1.2 \\
\hline & MW + impact crushing & 5.7 & 0.2 & 94.3 & 0,2 & 0.0 & - \\
\hline \multirow[t]{2}{*}{ SC_medium } & Impact crushing & 6.9 & 0.1 & 65.8 & 2.5 & 27.4 & 2.5 \\
\hline & MW + impact crushing & 10.1 & 0.3 & 88.5 & 1.0 & 1.3 & 1.3 \\
\hline \multirow[t]{2}{*}{ SC_fine } & Impact crushing & 5.5 & 0.3 & 29.0 & 0.2 & 65.5 & 0.1 \\
\hline & MW + impact crushing & 13.6 & 1.0 & 77.5 & 0.4 & 9.0 & 0.5 \\
\hline \multirow[t]{2}{*}{ S_medium } & Impact crushing & 8.4 & 0.1 & 65.1 & 1.3 & 26.4 & 1.4 \\
\hline & MW + impact crushing & 9.5 & 0.1 & 90.5 & 0.1 & 0.0 & - \\
\hline
\end{tabular}

Table 7

Fracture energy before impact crushing of concrete specimens SC_coarse, SC_medium, SC_fine and S_medium with and without a microwave (MW) pretreatment at 4.5 kW-30s.

\begin{tabular}{|c|c|c|c|c|}
\hline & & \multicolumn{3}{|c|}{$\begin{array}{l}\text { Fracture energy } \\
(\mathrm{Wh} / \mathrm{t})\end{array}$} \\
\hline & & Mean & $\begin{array}{l}\text { Standard deviation } \\
\text { of the mean }\end{array}$ & \%Relative decrease \\
\hline \multirow[t]{2}{*}{ SC_coarse } & Without MW pretreatment & 5.5 & 0.1 & \\
\hline & With MW pretreatment & 3.0 & 0.0 & 45.5 \\
\hline \multirow[t]{2}{*}{ SC_medium } & Without MW pretreatment & 10.4 & 0.3 & \\
\hline & With MW pretreatment & 6.2 & 0.4 & 40.4 \\
\hline \multirow[t]{2}{*}{ SC_fine } & Without MW pretreatment & 12.2 & 2.5 & \\
\hline & With MW pretreatment & 11.7 & 1.4 & 4.1 \\
\hline \multirow[t]{2}{*}{ S_medium } & Without MW pretreatment & 9.7 & 0.1 & \\
\hline & With MW pretreatment & 7.6 & 12 & 21.6 \\
\hline
\end{tabular}

\section{Results and discussion}

\subsection{Influence of the aggregate properties on the selective fragmentation performance of concrete samples}

\subsubsection{Results for impact crushing alone}

3.1.1.1. Influence of the size of the aggregates. By comparing fragment size distribution after impact crushing of silico-calcareous specimens SC_fine, SC_medium and SC_coarse, Fig. 3 shows that increasing aggregate size led to an increase in concrete fragmentation. This induced a reduction of the amount of particles with size greater than $20 \mathrm{~mm}$ but had almost no impact on the production of fines (amount of particles smaller than $2 \mathrm{~mm}$ ). These results are in line with those obtained with the Hopkinson bar testing (Table 4) since it was observed that an increase in the energy needed to fracture the concrete specimen correlated with a decrease of aggregates size distribution, the fracture energy being $5.5,10.4$ and 12.2 Wh/t for SC_coarse, SC_medium and SC_fine respectively. Similar results were found by several authors (Walker and Bolem, 1960; Cordon and Gillespie, 1963; Al-Oraimi et al., 2006) who all showed that the concrete strength increased with decreasing aggregates maximum size.

Regarding liberation degree, Table 5 shows an increase in the liberation degree of aggregates with an increase of aggregate size for silicocalcareous aggregates, the liberation degree being increased from $19.1 \%$ for SC_fine to $71.6 \%$ for SC_coarse. These results could be explained by the thickness of the Interfacial Transition Zone (ITZ). Indeed, some authors (Monteiro et al., 1985; Ping and Beaudoin, 1992; Elsharief et al., 2003) observed that the thickness of the ITZ becomes larger for larger aggregates. Since ITZ is considered to be the weak link in a concrete (Perry and Gillott, 1977; Giaccio and Zerbino, 1998; Scrivener et al., 2004; Akçaoğlu et al,, 2005), this increase in ITZ thickness for coarse aggregates could explain the observed decrease in sample fracture energy and the observed increase in liberation degree for coarse aggregates as their larger ITZ would lead to a weaker connection to the cement paste matrix, so when exposed to the same crushing conditions would experience a greater fragmentation and greater liberation.

3.1.1.2. Influence of the nature and mineralogy of the aggregates. Regarding the influence of the nature and mineralogy of the aggregates on impact crushing performances, Fig. 3 shows that for a similar aggregate distribution size (SC_medium vs S_medium), fragmentation of concrete was not influenced by the nature and mineralogy of the aggregates used in this study. These results are confirmed by the Hopkinson bar testing (Table 4) with similar fracture energy for SC_medium and S_medium. This observation is in line with results of several authors (Özturan and Çeçen, 1997; Wu et al., 2001) who found similar compressive strength values for normal strength concrete made with different type of aggregates. In particular, it was showed that in conventional concrete (compressive strength $<41 \mathrm{MPa}$ ) like the concrete specimens used in this study (as shown by Table 1), the properties of coarse aggregates rarely become strength-limiting, because this type of concrete mixtures typically corresponds to a water-cement ratio ( $\mathrm{w} / \mathrm{c}$ ratio) in the range of $0.5-0.7$ and within this range, the weakest components in concrete are the hardened cement paste and the transition zone between the cement paste and the coarse aggregates rather than the coarse aggregates itself (Kaplan, 1959; Mehta, 1986; de Larrard and Belloc, 
1992). However, for a high strength concrete (compressive strength $>41 \mathrm{MPa}$ ), researchers have noted that the hardened cement paste and the transition zone are no longer strength-limiting, but the ultimate strength of concrete is controlled by the mineralogy and the strength of the coarse aggregates (Beshr et al., 2003).

Regarding liberation degree, Table 5 shows that the use of silico-calcareous aggregates induced a lower liberation degree than the use of siliceous aggregates. This result could be explained by the presence of some chemical reactions between the aggregates and the cement paste. Indeed, it was observed by several authors (Maso, 1982; Ollivier et al., 1995; Tasong et al., 1999) that the microstructure in the IIZ may be affected by the chemical reactivity between aggregates and cement paste. In particular, it was found that calcareous aggregates are reactive with Portland cement paste, resulting in a superficial etching (Farran, 1956). Two explanations of this chemical reaction were found in the literature. According to Grandet and Ollivier (1980), the hydrate which reacts is calcium aluminate hydrate, forming calcium hydrocarboaluminate $\mathrm{C}_{3} \mathrm{~A} \cdot \mathrm{CaCO}_{3} \cdot 11 \mathrm{H}_{2} \mathrm{O}$. The other explanation was given by Monteiro and Mehta (1986) who reported that calcite reacts with calcium hydroxide, resulting in the formation of calcium carbonate with a varying composition of $\mathrm{CaCO}_{3} \cdot \mathrm{Ca}(\mathrm{OH})_{2} \cdot \mathrm{H}_{2} \mathrm{O}$. This reaction is limited to the ITZ due to the low mobility of carbonate ions but it leads to a more compact cement paste (Ollivier et al., 1995). Therefore, the bond strength around calcareous particles is increased. This increased bonding strength between cement paste and calcareous aggregates could then explain why the use of silico-calcareous aggregates induced a lower liberation degree than siliceous aggregates.

\subsubsection{Results for the microwave-assisted crushing process}

3.1.2.1. Influence of the size of the aggregates. Fig. 4 shows that the particle size distribution after concrete fragmentation tends to be very similar to the initial aggregate size distribution, meaning that a better aggregate liberation was reached. This was confirmed by results in Table 8 which shows that the microwave pretreatment allowed improving the liberation degree of aggregates after impact crushing, the liberation degree reaching even more than $90 \%$ for SC_coarse. These results are in line with the ones obtained by several authors (Figg, 1974; Akbarnezhad et al., 2011; Lippiatt and Bourgeois, 2012). Indeed, aggregates and cement phase exhibit differences in dielectric and thermal properties, which induce different thermal expansion when submitted to microwaves. This leads to the development of stresses which are favorable for phase boundary weakening during rapid heating. Moreover, ITZ around aggregate particles is suspected to play a key role in the embrittlement behavior of concrete during microwave heating as it has a higher porosity and higher $\mathrm{w} / \mathrm{c}$ ratio. Indeed, the energy absorbed by a material increases significantly with an increase in the water content and water heating gives rise to both heat and stress sources, therefore the ITZ is expected to heat up faster when concrete is exposed to microwaves. As a result, higher differential thermal stresses may develop at the ITZ, leading to a more efficient removal of the adhering mortar (Akbarnezhad et al., 2011).

Comparing results for fracture energy and liberation degree of aggregates from all samples has to be performed with particular care since these two parameters have an ultimate limit (also called "value to reach"), being $0 \mathrm{Wh} / \mathrm{t}$ and $100 \%$ respectively. This means that a simple comparison of the decrease or increase rate cannot be done since the improvement potential was physically limited by these values. For example, the liberation rate of aggregates after impact crushing alone of SC_coarse and SC_fine is $71.6 \%$ and $19.1 \%$ respectively meaning that the gap to reach the limit value (100\%) was only of $\mathbf{2 8 . 4 \%}$ for SC_coarse against $\mathbf{8 0 . 9 \%}$ for SC_fine. Therefore, it was chosen to use the parameters "\%relative decrease" for fracture energy and "\%relative increase" for liberation degree of aggregates which are defined as the following:

- For fracture energy:

\%Relative decrease $=100 \times \frac{\text { Fracture energy with MW treatment-Fracture energy without MW treatment }}{\text { Value to reach-Fracture energy without MW treatment }}$.

- For liberation degree of aggregates:

\%Relative increase $=100 \times \frac{\text { Liberation degree with MW treatment-Liberation degree without MW treatment }}{\text { Value to reach-Liberation degree without MW treatment }}$.

The influence of the particle size distribution of the aggregates on the performance of the microwave heating regarding concrete fragmentation was evaluated with these two parameters (Tables 7 and 8). Results show that the coarser the aggregate size distribution, the more effective was the MW pretreatment with an objective increase in liberation degree ranging from 29.7\% for SC_fine to 65.1\% for SC_coarse. This observation is consistent with works performed by Elsharief et al. (2003) who reported that reducing the aggregate size leads to lower porosity and a higher unhydrated particle content in the ITZ due to the fact that large aggregate particles tends to accumulate more bleed water around them than smaller aggregate particles, leading to a higher local w/c ratio around large aggregate particles. Moreover, since it was previously reported that the thickness of the ITZ becomes larger for larger aggregates, it could then be expected that microwave heating would be more effective for coarse aggregates in terms of liberation.

3.1.2.2. Influence of the nature and mineralogy of the aggregates. The aggregates mineralogy has no clear impacts on the performance of a microwave heating pretreatment for concrete fragmentation (Tables $6,7,8$ ). Indeed, similar evolution of the fragment size distribution was observed in both cases. They also led to a similar liberation degree of aggregates in fragment size of $2-20 \mathrm{~mm}$ but a greater increase was observed with silicocalcareous aggregates compared to siliceous ones ( $59.0 \%$ against $18.7 \%$ respectively). Since lower liberation degree with silico-calcareous aggregates compared to siliceous ones was previously explained by the chemical reactivity between calcareous aggregates and cement paste, these results seem to show that microwave heating allows breaking of these bonds. However, further tests are needed to confirm this explanation. 


\subsection{Influence of the microwave heating pretreatment operating conditions}

A series of experiments was conducted on the no-slump concrete waste with the objective to evaluate the influence of the operating conditions of the microwave pretreatment on concrete fragmentation after impact crushing. This concrete waste was formulated in a very different way from the lab-cast samples, in particular with different aggregate size distribution and aggregate mineralogy and with a different water/cement ratio. Regarding the $\mathbf{w} / \mathrm{c}$ ratio, it is 0.16 for the no-slump concrete waste. Since water in materials was previously reported to have a major role when exposed to microwaves, this allows testing of unfavorable conditions for concrete embrittlement through the use of microwaves and thereby the robustness of the technique.

Four operating conditions of microwave embrittlement before impact crushing were tested with power value fixed either at $1 \mathrm{~kW}$ or $4.5 \mathrm{~kW}$ and exposure time fixed either at $0.5 \mathrm{~min}$ or $5 \mathrm{~min}$. Results are presented in Table 9. A statistical comparison of the operating conditions of the microwave heating was firstly performed and secondly results were compared to the reference "impact crushing alone", that is why only mean values are given for this latter condition.

The plotting of the probability distribution relative to "mass percentage of 2-20 mm fragments" highlights the presence of two population groups (Fig. 5): the first one at microwave heating conditions of $1 \mathrm{~kW}-0.5 \mathrm{~min}$ and of $1 \mathrm{~kW}-5 \mathrm{~min}$; and the second one at microwave heating conditions of $4.5 \mathrm{~kW}-0.5 \mathrm{~min}$ and $4.5 \mathrm{~kW}-5 \mathrm{~min}$. When drawn separately (Fig. 6) it is observed that both probability distributions can be fitted by a log-normal distribution, the probability of appearance relative to the impact crushing alone being $61.4 \%$ in the first group and only $0.02 \%$ in the second group. Parameters of these functions were estimated and are given in Table 10. These results show that there may be a limit value of heating power necessary to embrittle concrete waste samples i.e. to generate stresses high enough inside the material to induce noticeable cracks. When the heating power is higher than this limit value then the additional absorbed energy may be used to enhance the embrittlement of the cement matrix, since it is observed from Table 9 an increase in the production of fines and a drastic decrease in the production of fractions $>20$ mm for the maximum heating condition ( $348.9 \mathrm{kWh} / \mathrm{t}$ ) compared to the other conditions.

Regarding "liberation degree of aggregates in the $2-20 \mathrm{~mm}$ fraction", Fig. 7 shows that the probability distribution can be described by a log-normal distribution, whose parameters are given in Table 10 . This means that the microwave operating conditions do not have a significant influence on liberation degree of aggregates. Moreover, the probability of appearance relative to the impact crushing alone is only $0.02 \%$ which underlies a significant difference between liberation degrees obtained with a microwave pretreatment and from the one obtained without pretreatment.

Results obtained in this second series of experiments show that the microwave heating is an effective weakening technique for improving selective fragmentation after impact crushing even when the material was exposed to a very low energy microwave heating (7.1 $\mathrm{kWh} / \mathrm{t}$ ). Moreover, an increase in this energy from $7.1 \mathrm{kWh} / \mathrm{t}$ to $348.9 \mathrm{kWh} / \mathrm{t}$ enhanced concrete fragmentation but had no influence on aggregates liberation degree. This is an important result since it could mean that there is a threshold of microwave heating energy to reach in order to liberate aggregates; above this threshold an increase in the microwave heating energy would have an influence only on the intensity of the fragmentation phenomenon and not on the liberation. According to the results obtained in this study, this threshold is lower than $7.1 \mathrm{kWh} / \mathrm{t}$. By applying an appropriate comminution treatment after a low microwave heating step, it could then be possible to recover aggregates of high-quality and to reach the objective of increasing concrete waste recycling by producing recycled aggregates with properties similar to the natural ones.

\section{Discussion on the applicability of the proposed process to treat concrete from construction and demolition waste}

These series of experiment were performed on lab-made concrete specimens but concrete from construction and demolition waste exhibits higher complexity and heterogeneity. It is then important to look into the applicability of the proposed process for treating this concrete. In particular:

- Concrete waste is a very heterogeneous material especially regarding aggregates, for example, due to the fact that aggregates for concrete production are extracted near concrete production sites and

\section{Table 8}

Liberation degree of aggregates in fragment size of 2-20 mm after impact crushing of concrete specimens SC_coarse, SC_medium, SC_fine and S_medium with and without a microwave (MW) pretreatment at $4.5 \mathrm{~kW}-30 \mathrm{~s}$.

\begin{tabular}{lllll} 
& & \multicolumn{3}{l}{$\begin{array}{l}\text { Liberation degree of aggregates in } \\
\text { fragment size of 2-20 mm (wt.\%) }\end{array}$} \\
\cline { 3 - 5 } & & Mean & $\begin{array}{l}\text { Standard deviation } \\
\text { of the mean }\end{array}$ & $\begin{array}{l}\text { \%Relative } \\
\text { increase }\end{array}$ \\
\hline SC_coarse & Impact crushing & 71.6 & 1.3 & \\
& MW + impact crushing & 90.1 & 4.0 & 65.1 \\
SC_medium & Impact crushing & 45.3 & 3.5 & 59.0 \\
& MW + impact crushing & 77.6 & 1.5 & 29.7 \\
SC_fine & Impact crushing & 19.1 & 1.8 & 18.7 \\
& MW + impact crushing & 43.1 & 0.3 & \\
S_medium & Impact crushing & 65.7 & 2.2 & \\
& MW + impact crushing & 72.1 & 0.1 & \\
\hline
\end{tabular}

their properties vary with the geological characteristics of the region of extraction. Since this series of experiments has underlined the feasibility of a microwave heating stage before impact crushing for lowering the concrete fracture energy and for producing liberated aggregates (i.e. high quality aggregates) irrespective of the nature of the aggregates used in concrete, it can then be stated that the proposed process is a robust technical solution that can be used for a high-quality concrete waste recycling.

- Concrete waste can include steel reinforcement bars. This reinforcement will not damage the microwave magnetrons since industrial magnetrons are protected from reflected microwave power but it may affect the operation of the microwave heating step. Indeed, it has been reported that part of the microwave energy is reflected from the reinforcement and more energy is dissipated between the concrete front surface and the location of the reinforcement (Lagos et al., 1995; Clemeña, 2004). However, the proposed process based on microwave heating followed by impact crushing will include a concrete recycling loop in order to optimize treatment of concrete blocks. The use of a magnetic separator just before the recycling loop should remove all metallic inclusions and guarantee an effective microwave treatment of concrete waste.

- Even if concrete from demolition waste has been in use for several years, it is expected that microwave heating will induce a similar embrittlement behavior as the one observed in this study. Indeed, several studies have showed that dielectric properties of concrete are relatively stable over time after the curing time (Lai et al., 2009; Jamil et al., 2013). Moreover, stresses induced 


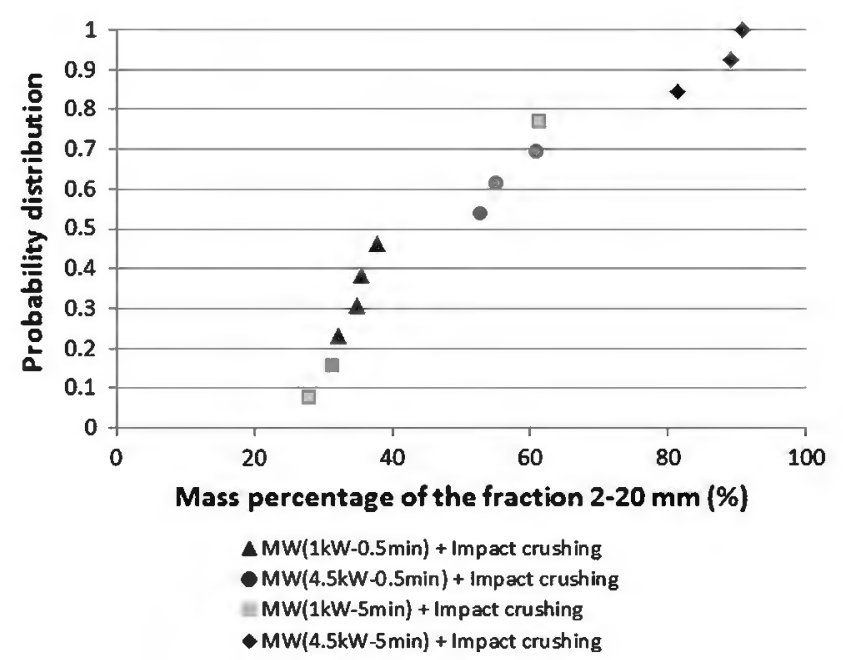

Fig. 5. Probability distribution of the $2-20 \mathrm{~mm}$ mass fraction produced by microwave heating followed by impact crushing. by microwave heating are also due to the water content in the ITZ around aggregate particles and this bound water content will not change over time.

\section{Conclusions}

This work looked at assessing the efficiency of a microwave heating before impact crushing for producing high-quality aggregates (i.e. without cement paste) and then for improving concrete waste recycling, showing the possibility of moving from the current down-cycling to a future up-cycling of concrete waste. Indeed, the microwave weakening pretreatment was proven to be effective irrespective of the nature of the aggregates used in concrete and even when the material was exposed to a very low microwave heating energy. Further tests including a mechanical rubbing stage after microwave weakening and impact crushing have to be performed since it is expected that this rubbing stage should improve the aggregate liberation degree and fine fraction production by removing the remaining adherent cement paste on aggregates.

Table 9

Results of the experiments relative to the microwave-assisted crushing process performed on the no-slump concrete waste.

\begin{tabular}{|c|c|c|c|c|c|}
\hline \multirow{3}{*}{$\begin{array}{l}\text { Absorbed energy } \\
(\mathrm{kWh} / \mathrm{t})\end{array}$} & \multirow{3}{*}{$\frac{\text { Qualitative factor }}{\text { Operating conditions }}$} & \multicolumn{4}{|l|}{ Results } \\
\hline & & \multicolumn{3}{|c|}{ Fragment size distribution } & \multirow{2}{*}{$\begin{array}{l}\text { Liberation degree of aggregates in } \\
\text { fragment size of } 2-20 \mathrm{~mm} \\
\text { (wt\%) }\end{array}$} \\
\hline & & $\begin{array}{l}<2 \mathrm{~mm} \\
\text { (wt.\%) }\end{array}$ & 2-20 mm (wt.\%) & $\begin{array}{l}>20 \mathrm{~mm} \\
\text { (wt.\%) }\end{array}$ & \\
\hline - & Impact crushing alone & 3.0 & 36.0 & 61.0 & 34.7 \\
\hline \multirow{4}{*}{7.1} & $1 \mathrm{~kW}-0.5 \mathrm{~min}$ & 3.6 & 37.8 & 58.5 & 59.9 \\
\hline & & 3.5 & 34.9 & 61.6 & 50.5 \\
\hline & & 3.1 & 32.1 & 64.8 & 83.4 \\
\hline & & 4.3 & 35.4 & 60.3 & 52.3 \\
\hline \multirow[t]{3}{*}{32.4} & $4.5 \mathrm{~kW}-0.5 \mathrm{~min}$ & 4.7 & 52.8 & 42.4 & 67.7 \\
\hline & & 3.6 & 55.2 & 41.2 & 46.1 \\
\hline & & 3.8 & 60.9 & 35.3 & 44.6 \\
\hline \multirow[t]{3}{*}{77.2} & $1 \mathrm{~kW}-5 \mathrm{~min}$ & 4.3 & 61.3 & 34.4 & 44.8 \\
\hline & & 3.5 & 27.9 & 68.6 & 48.3 \\
\hline & & 3.4 & 31.3 & 65.3 & 53.9 \\
\hline \multirow[t]{3}{*}{348.9} & $4.5 \mathrm{~kW}-5 \mathrm{~min}$ & 6.4 & 90.7 & 2.9 & 53.9 \\
\hline & & 6.1 & 89.2 & 4.6 & 42.4 \\
\hline & & 5.7 & 81.3 & 13.0 & 56.1 \\
\hline
\end{tabular}

(a)

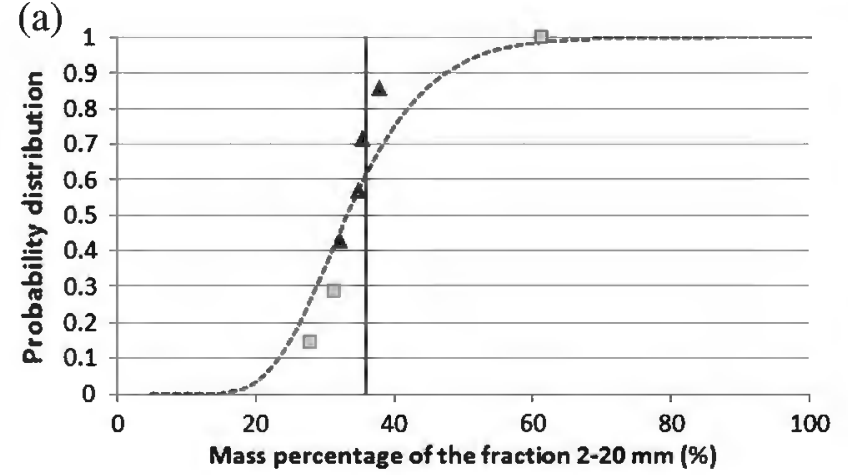

- $M W(1 k W-0.5 \mathrm{~min})+$ Impact crushing

- $M W(1 k W-5 m i n)+I m p a c t$ crushing

---- MW + Impact crushing - log normal distribution

- Impact crushing alone (b)

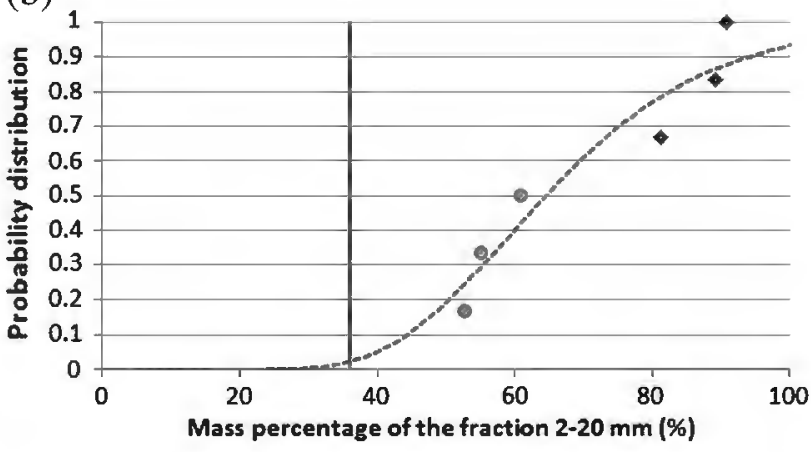

- $M W(4.5 k W-0.5 \mathrm{~min})+$ Impact crushing

- MW(4.5kW-5min) + Impact crushing

----. MW + Impact crushing - log normal distribution

Impact crushing alone

Fig. 6. Probability distribution of the 2-20 mm mass fraction produced after impact crushing with and without microwave pre-treatment. (a) For MW conditions of $1 \mathrm{~kW}-0.5$ min and of $1 \mathrm{~kW}-5 \mathrm{~min}$; (b) For MW conditions of $4.5 \mathrm{~kW}-0.5 \mathrm{~min}$ and of $4.5 \mathrm{~kW}-5 \mathrm{~min}$. 
Table 10

Parameters of the log-normal probability distribution.

\begin{tabular}{lll}
\hline & Mean $\mu(\%)$ & $\begin{array}{l}\text { Standard } \\
\text { deviation } \sigma\end{array}$ \\
\hline $\begin{array}{c}\text { Mass percentage of the } 2-20 \mathrm{~mm} \text { fraction }-\mathrm{MW} \\
\text { conditions of } 1 \mathrm{~kW}-0.5 \mathrm{~min} \text { and of } 1 \mathrm{~kW}-5 \mathrm{~min}\end{array}$ & 36.6 & 1.3 \\
$\begin{array}{c}\text { Mass percentage of the } 2-20 \mathrm{~mm} \text { fraction }-\mathrm{MW} \\
\text { conditions of } 4.5 \mathrm{~kW}-0.5 \mathrm{~min} \text { and of } 4.5 \mathrm{~kW}-5 \mathrm{~min}\end{array}$ & 69.0 & 1.3 \\
$\begin{array}{c}\text { Liberation degree of the aggregates } \\
\text { in the 2-20 mm fraction }\end{array}$ & 53.5 & 1.2 \\
\hline
\end{tabular}

Probability density of $\mathrm{x}$ is defined as: $\mathrm{P}(\mathrm{x})=\frac{1}{\mathrm{x} \cdot \sigma \cdot \sqrt{2}-\pi} \exp \left\{-\frac{1}{2}\left[\frac{\ln (\mathrm{x})-\mu}{\sigma}\right]^{2}\right\}$ with $\mu$ : mean and $\sigma$. standard deviation.

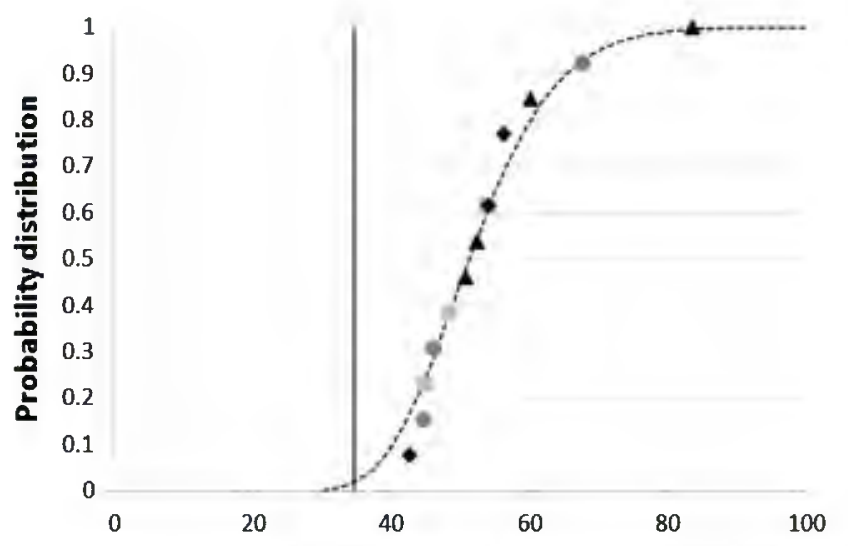

Liberation degree of the aggregates in the fraction $2-20 \mathrm{~mm}(\%)$

- $M W(1 k W-0.5 m i n)+1 m p a c t$ crushing

- $M W(4.5 k W-0.5$ min $)+$ Impact crushing

- $M W(1 \mathrm{~kW}-5 \mathrm{~min})+$ Impact crushing

- MW(4.5kW-5min) + Impact crushing

-.-.- MW + Impact crushing - log normal distribution

- Impact crushing alone

Fig. 7. Probability distribution of the liberation degree of the aggregates in the $2-20 \mathrm{~mm}$ fraction produced after impact crushing with and without microwave pre-treatment.

\section{Acknowledgments}

The authors wish to thank the French Research Agency ANR for their financial support through the COFRAGE project (ANR-Ecotech 2009), as well as all the partners of the project (Picheta, Colas, CNRS - IMS and Selfrag AG). They also wish to thank Pascal Auger and Mohamed Djemil for their technical assistance.

\section{References}

Akbarnezhad, A., Ong, K.C.G., Zhang, M.H., Tam, CT., Foo, T.W.J., 2011. Microwave-assisted beneficiation of recycled concrete aggregates. Constr. Build, Mater. 25, 3469-3479.

Akçaoğlu, T., Tokyay, M., Çelik, T., 2005. Assessing the ITZ microcracking via scanning electron microscope and its effect on the failure behavior of concrete. Cem. Concr. Res. 35 358-363.

Al-Oraimi, S.K., Taha, R., Hassan, H.F., 2006. The effect of the mineralogy of coarse aggregate on the mechanical properties of high-strength concrete. Constr. Build, Mater. 20 499-503.

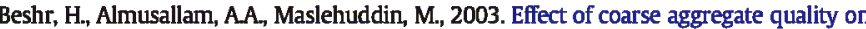
the mechanical properties of high strength concrete. Constr. Build. Mater. 17, 97-103. Bourgeois, F.S., Banini, G.A., 2002. A portable load cell for in-situ ore impact breakage testing. Int. J. Miner. Process. 65, 31-54.

Clemeña, G.G., 2004. Short-pulse radar methods, In: CRC Press LLC (Ed.), Handbook on Nondestructive Testing of Concrete, 2 nd ed. (21 pp.).

Cordon, WA, Gillespie, H.A, 1963. Variables in concrete aggregates and Portland cement paste which influence the strength of concrete. Amer. Concr. Inst. J. 60, 1029-1052.

de Larrard, F., Belloc, A. 1992. Are small aggregates really better for making high-strength concrete? Cement Concr. Aggr. 14, 62-66.

Elsharief, A, Cohen, M.D., Olek, J, 2003. Influence of aggregate size, water cement ratio and age on the microstructure of the interfacial transition zone. Cem. Concr. Res. $33,1837-1849$.

Farran, J., 1956. Contribution minéralogique à l'étude de l'adhérence entre les constituants hydratés des ciments et les matériaux enrobés. Rev. Mater. Constr. 490-492

Figg, J., 1974. Microwave heating in concrete analysis. J. Appl. Chem. Biotechnol. 24, 143-155.

Giaccio, G., Zerbino, R, 1998. Failure mechanism of concrete: combined effects of coarse aggregates and strength level. Adv. Cem. Based Mater. 7, 41-48.

Grandet, J., Ollivier, J.P., 1980. Etude de la formation du monocarboaluminate de calcium hydrate au contact d'un granulat calcaire dans une pate de ciment portland. Cem. Concr. Res. 10, 759-770.

Jamil, M., Hassan, M.K., Al-Mattarneh, H.M.A., Zain, M.F.M., 2013. Concrete dielectric properties investigation using microwave nondestructive techniques. Mater. Struct. 46 77-87.

Kaplan, M.F., 1959. Flexural and compressive strength of concrete as affected by the properties of coarse aggregates. Am. Concr. Inst. J. 55, 1193-1208.

Kim, K.H., Cho, H.C., Ahn, J.W., 2012. Breakage of waste concrete for liberation using autogenous mill. Miner. Eng. 35, 43-45.

Lagos, L.E., Li, W., Ebadian, M.A., White, T.L., Grubb, R.G., Foster, D., 1995. Heat transfer within a concrete slab with a finite microwave heating source. Int. J. Heat Mass Transf. 38, 887-897.

Lai, W.L., Kou, S.C., Tsang, W.F., Poon, C.S., 2009. Characterization of concrete properties from dielectric properties using ground penetrating radar. Cem. Concr. Res. 39, 687-695.

Lippiatt, N., Bourgeois, F., 2012. Investigation of microwave-assisted concrete recycling using single-particle testing. Miner. Eng. 31, 71-81.

Maso, J.C, 1982. La Liaison Pâte-Granulats. In: Sauterey, R. (Ed.), Baron, J. Le Bêton Hydraulique, Paris, pp. 247-259.

Mehta, P.K., 1986. Concrete: Structure, Properties and Materials, 1st ed. Prentice-Hall, New Jersey, Englewood Cliffs.

Mehta, P.K., 2001. Reducing the environmental impact of concrete, Concr. Int, 61-66.

Mehta, P.K., Monteiro, P.J.M., 2005. Concrete: Microstructure, Properties, and Materials, 3rd ed. Mc Graw Hill, New York

Menard, Y., Bru, K., Touze, S., Lemoign, A. Poirier, J.E., Ruffie, G., Bonnaudin, F., Von Der Weid, F., 2013. Innovative process routes for a high-quality concrete recycling Waste Manage. 33, 1561-1565.

Monteiro, P.J.M., Mehta, P.K., 1986. Interaction between carbonate rock and cement paste. Cem. Concr. Res. 16, 127-134.

Monteiro, P.J.M., Maso, J.C., Ollivier, J.P., 1985. The aggregate-mortar interface. Cem. Concr Res. 15, 953-958.

NF EN 1097-6, 2001. Essais pour déterminer les caractéristiques mécaniques et physiques des granulats.

NF P18-545, 2001. Granulats - Eléments de définition, conformité et codification.

Noguchi, T., Kitagaki, R., Tsujino, M., 2011. Minimizing environmental impact and maximizing performance in concrete recycling. Struct. Concr. 12, 36-46.

Ollivier, J.P., Maso, J.C., Bourdette, B., 1995. Interfacial transition zone in concrete. Adv. Cem. Based Mater. 2, 30-38.

Özturan, T., Çeçen, $C_{\text {. }}$ 1997. Effect of coarse aggregate type on mechanical properties of concretes with different strengths. Cem, Concr. Res. 27, 165-170.

Perry, C., Gillott, J.E., 1977. The influence of mortar-aggregate bond strength on the behaviour of concrete in uniaxial compression. Cem. Concr. Res. 7, 553-564

Ping, X., Beaudoin, J.J., 1992. Effects of transition zone microstructure on bond strength of aggregate-portland cement paste interfaces. Cem. Concr. Res. 22, 23-26.

Scrivener, K.L., Crumbie, A.K., Laugesen, P., 2004. The interfacial transition zone (ITZ) between cement paste and aggregate in concrete. Interface Sci. 12, 411-421.

Tasong, W.A., Lynsdale, C.J., Cripps, J.C., 1999. Aggregate-cement paste interface: part I. Influence of aggregate geochemistry. Cem. Concr. Res. 29, 1019-1025.

Tomas, J., Schreier, M., Gröger, T., Ehlers, S., 1999. Impact crushing of concrete for liberation and recycling. Powder Technol. 105, 39-51.

Tsujino, M., Kitagaki, R., Noguchi, T., Nagai, H., Kunieda, Y., 2008. Completely Recyclable Concrete of Aggregate-Recovery Type by Using Microwave Heating Technology. 522-539 (Ho Chi Minh City, Vietnam, 11-13 November).

Ulsen, C., Kahn, H., Hawlitschek, G., Masini, E.A., Angulo, S.C., 2013. Separability studies of construction and demolition waste recycled sand. Waste Manage. 33, 656-662.

Walker, S., Bolem, D. 1960. Effect of aggregate size on properties of concrete. Amer. Concr. Inst. J. 57, 283-298.

Wu, K., Chen, B., Yao, W. Zhang, D., 2001. Effect of coarse aggregate type on mechanical properties of high-performance concrete. Cem. Concr. Res. 31, 1421-1425. 